\title{
Cinema, teatro, criatividade: metodologias ativas na formação discente do PIBID Pedagogia-UFV
}

\author{
Cinema, theater, creativity: active methodologies in \\ student training of the PIBID Pedagogy-UFV
}

\section{Emiliana Maria Diniz Marques, Rita de Cássia de Souza, Vanessa Maciel Zico*}

Universidade Federal de Viçosa (UFV), Viçosa, MG, Brasil

\section{Resumo}

O presente trabalho é resultado das reflexões suscitadas a partir de um curso intitulado "Cinema, Teatro e Criatividade: experiências possíveis para reinvenções na escola", oferecido para 20 estudantes bolsistas do Programa Institucional de Bolsa de Iniciação à Docência - PIBID, vinculado ao curso de Pedagogia da Universidade Federal de Viçosa UFV. O curso contemplou os objetivos de: refletir sobre o encontro do cinema e do teatro com a educação, problematizando a sua utilização nas escolas; ampliar o contato das estagiárias do PIBID com experiências relacionadas ao cinema e às artes cênicas; e desenvolver atividades práticas para o trabalho com cinema e jogos teatrais na sala de aula. Foram ao todo dez encontros que, em conjunto, abarcaram atividades prático-teóricas envolvendo jogos e improvisações teatrais, brinquedos ópticos, exibição de filmes de curta metragem, produção de vídeos, contação de histórias, visita ao Museu da Comunicação da UFV,

EMDM: Mestrado em educação, e-mail: emiliana@ufv.br

RCS: Doutorado em educação, e-mail: ritasouza@ufv.br

VMZ: Pós-graduada em Mediação em Arte, Cultura e Educação, e-mail: vanessa.zico@gmail.com 
reflexões sobre a atuação profissional na sala de aula e relatos e trocas de experiências. Em todos os encontros, buscou-se estimular o protagonismo das estagiárias em relação às ações desenvolvidas por elas nas escolas com a apropriação das atividades de cinema e teatro realizadas no curso. Os impactos deste foram avaliados a partir de relatórios mensais nos quais as pibidianas apresentavam o que observaram e realizaram na atuação nas escolas. Acreditamos que o curso cumpriu o seu objetivo de fomentar novas experiências educativas que fossem inspiradoras para a prática das pibidianas de Pedagogia em atuação nas escolas básicas do ensino fundamental, hoje e no futuro.

Palavras-chave: Cinema. Teatro. Educação. Pibid. Pedagogia.

\section{Abstract}

The present study is the result of the reflections raised from the course titled "Cinema, Theater and Creativity: possible experiences for reinventions in schools" offered to 20 scholarship students of the PIBID - Institutional Scholarship Program to Teaching Initiation (Programa Institucional de Bolsa de Iniciação à Docência), linked to the course of Pedagogy of the Federal University of Viçosa - UFV. The course included the following objectives: to think over the combination of cinema and theater with education questioning their use in schools; expand the contact of the trainees of the PIBID with experiences related to the cinema and performing arts; and to develop practical activities to work with film and theater games in the classroom. Furthermore, the course consisted of ten meetings that together covered practical and theoretical activities involving games and theater improvisations, optical toys, displaying short films, video production, storytelling, visiting the Museum of Communication of the UFV, thinking about professional performance in the classroom, reports and exchange of experiences. All meetings sought to stimulate the role of the trainees regarding their activities in schools with the appropriation of cinema and theater activities performed in the course. The impacts were evaluated from monthly reports in which the "pibidianas" (the trainees) presented what they had observed and performed in the schools. We believe that the course has fulfilled its goal of promoting new educational experiences that might be inspiring for the trainees of the Pedagogy course whilst performing in basic primary schools today and in the future.

Keywords: Cinema. Theatre. Education. Pibid. Pedagogy. 


\section{Introdução}

A arte, para permanecer arte, deve permanecer um fermento de anarquia, de escândalo, de desordem. A arte é por definição um elemento perturbador dentro da instituição. Ela não pode ser concebida pelo aluno sem a experiência do 'fazer' e sem contato com o artista, o profissional, entendido como corpo 'estranho' à escola, como elemento felizmente perturbador de seu sistema de valores, de comportamentos e de suas normas relacionais (BERGALA, 2008, p. 30)

O presente trabalho é resultado das reflexões suscitadas a partir de um curso intitulado "Cinema, Teatro e Criatividade: experiências possíveis para reinvenções na escola”, oferecido para 20 estudantes bolsistas do Programa Institucional de Bolsa de Iniciação à Docência - PIBID, vinculado ao curso de Pedagogia da Universidade Federal de Viçosa (UFV). Este texto assume o objetivo de refletir sobre o uso de metodologias ativas no ensino superior, consideradas em diálogo com métodos artístico-teatrais e do ensino de cinema, voltadas para a formação das educadoras dos anos iniciais da Educação Básica.

O PIBID, criado em 2007 pelo Ministério da Educação, atua da seguinte forma:

O programa oferece bolsas de iniciação à docência aos alunos de cursos presenciais que se dediquem ao estágio nas escolas públicas e que, quando graduados, se comprometam com o exercício do magistério na rede pública. O objetivo é antecipar o vínculo entre os futuros mestres e as salas de aula da rede pública. Com essa iniciativa, o Pibid faz uma articulação entre a educação superior (por meio das licenciaturas), a escola e os sistemas estaduais e municipais (PIBID, Apresentação MEC, s.d; s.p).

No curso de Pedagogia da Universidade Federal de Viçosa (UFV) há três subgrupos do Pibid sob a coordenação de três professoras. Num destes subgrupos, a coordenação percebia que havia uma significativa repetição do modus operandi escolar quando as pibidianas aplicavam a 
regência em sala. Ou seja, as bolsistas propunham atividades muito parecidas às que viam as professoras realizarem em classe.

Quando foi realizado este curso, no primeiro semestre do ano de 2016, as pibidianas atuavam em quatro escolas públicas do município de Viçosa-MG, nos primeiros cinco anos do ensino fundamental. O espaço escolar destas instituições é bastante precário. Nenhuma delas possui jardim, horta, parque, teatro, auditório, quadra ou ginásio de esportes. Salvo raras exceções, a quase totalidade das atividades é feita dentro de sala de aula, com as crianças em carteiras enfileiradas, envolvidas em atividades de leitura, escrita e operações matemáticas. Durante este período, não houve nenhum tipo de excursão nas escolas e, nas poucas atividades artístico-culturais realizadas, eram as professoras e pibidianas que faziam a decoração e confeccionavam painéis, convites e lembranças dos eventos. Até mesmo as atividades teatrais eram escolhidas pelas professoras e bolsistas e encenadas por elas, com alguma ajuda das crianças.

Em visita às escolas, percebemos que a demanda era de que as pibidianas auxiliassem em trabalhos extras (como recortar, colar, decorar, entre outros) e, principalmente, atuassem junto a estudantes considerados mais atrasados nas atividades escolares. Pedia-se às pibidianas que sentassem junto a estes estudantes para auxiliar nas tarefas escolares e, em alguns casos, isso era feito inclusive fora da sala de aula, "para não prejudicar as atividades da classe" como afirmavam as professoras das escolas. Foram feitas diversas reuniões com as supervisoras do PIBID nas escolas, professoras e diretoras para encontrarmos uma linguagem em comum, em que, apesar de conhecermos a demanda das escolas por este atendimento a alguns estudantes, isso fosse evitado e que o trabalho das pibidianas fosse feito em classe, envolvendo todos os estudantes.

Além disso, defendemos que as atividades realizadas nas escolas propiciassem mais protagonismo, autonomia e criatividade das crianças. No entanto, não fazia sentido que isso fosse solicitado, se as próprias pibidianas não soubessem como fazê-lo. Considerando fundamental que, neste processo de formação docente, as bolsistas tivessem a oportunidade de experienciar outras práticas formativas, foi oferecido o curso que 
apresentamos neste artigo. No curso, realizamos atividades com o objetivo de, através do cinema e do teatro, favorecer o desenvolvimento da criatividade e da autonomia entre as pibidianas visando sempre a transposição das atividades para o ambiente de uma sala de aula do ensino fundamental.

\section{Referencial Teórico}

Usamos o artigo "Notas sobre a experiência e o saber de experiência" de Jorge Larossa Bondía (2002) como motivador para o curso. Neste sentido, mais do que discutir e apresentar teorias sobre o ensino, buscamos criar situações vivenciais que favoreciam o despertar da experiência: "A experiência é o que nos passa, o que nos acontece, o que nos toca. Não o que se passa, não o que acontece, ou o que toca. A cada dia se passam muitas coisas, porém, ao mesmo tempo, quase nada nos acontece." (BONDÍA, 2002, p. 21). A experiência da qual se refere o autor não é algo que venha de fora para dentro, não é imposta, não é dirigida, ela depende, fundamentalmente, de um sujeito que se permita ser tocado, exposto, que tenha receptividade e disponibilidade para vivenciá-la. Assim também, a experiência é individual e intransferível. Neste sentido, tudo que poderíamos fazer era facilitar o processo, promover atividades vivenciais que favorecessem a criação de sentido para as pibidianas em processo de formação.

Acreditamos que, de maneira nem sempre consciente, os professores fazem o que viram ser feito, repetindo as práticas de seus professores. Ao discutirem os saberes envolvidos na prática docente, Tardif, Lessard e Lahaye chamam a atenção para os saberes da experiência: "Esses saberes brotam da experiência e são por ela validados. Eles incorporam-se à vivência individual e coletiva sob a forma de habitus e de habilidades, de saber-fazer e de saber-ser" (1991, p. 220). Neste sentido, era fundamental que as pibidianas passassem por um processo formativo que favorecesse a criatividade, a autonomia e o protagonismo destas de tal forma que elas 
vissem a possibilidade de levar tais experiências para as salas de aula em que atuavam.

O que empobrece muito o ato de educar é a quase ausência de propostas que impliquem atividades desafiadoras aos alunos. Em geral, só lhes cobram repetições. Dessa forma, eles leem, captam as ideias centrais, escrevem o que entenderam dos autores e recebem a nota considerada justa, pelo professor. [...] Aprender fazendo, agindo, experimentando é o modo mais natural, intuitivo e fácil de aprender (PEREIRA, 2004, p. 06).

Acrescenta-se ainda que, atualmente, no curso de Pedagogia da UFV não existe uma disciplina obrigatória envolvendo arte na educação. As disciplinas são predominantemente teóricas e, conforme pesquisas na área, podemos inferir que esses dados não são especificidades da UFV.

Observa-se que as aulas na Graduação em Pedagogia ainda se restringem a um tipo de conteúdo baseado no intelecto do aluno, em detrimento à ação do corpo, à sensibilidade e ao afeto dos alunos, imperando o silêncio, a leitura e a absorção dos conteúdos selecionados e organizados pelo professor. Por conta disso, a organização do currículo escolar e a prática pedagógica no ensino fundamental tendem a reproduzir os mesmos modelos aprendidos nos campos da formação inicial do educador. Ou seja, sem uma vivência participativa em arte, torna-se difícil para este profissional estimular a prática artística e o potencial criativo dos seus educandos no cotidiano escolar. Por outro lado, apesar da LDB 9.394, de 1996, garantir a obrigatoriedade do ensino de artes nas escolas, observa-se que a presença do educador licenciado em artes (teatro, dança, música e artes visuais) ainda é bastante restrita em todo o território nacional, cabendo aos pedagogos o ensino deste campo tão pouco tratado em sua formação (CANDA e BATISTA, 2009, p. 109 e 110).

Diante do exposto, havia o desafio de realizar um curso que trouxesse atividades práticas e passíveis de serem apropriadas e desenvolvidas pelas estagiárias na escola. Ao mesmo tempo, pretendia-se promover reflexões sobre o cotidiano da sala de aula, sobre as práticas pedagógicas 
vigentes na escola, o papel do teatro e do cinema no cotidiano escolar e a situação do corpo do estudante ao longo da sua estadia na escola.

João Batista Freire destaca que:

Há muito tempo, institui-se que a escola seria fechada, silenciosa, dividida, assim como é hoje, em disciplinas. Os professores seriam casmurros, as paredes descoloridas, e haveria muitas paredes. Os alunos ficariam trancados nessas salas e confinados em reduzidos espaços de meio metro quadrado para cada um deles, sentados durante horas e horas à frente de uma pequena mesa. Os contatos com outros alunos seriam mínimos, só se poderia falar com autorização dos professores, o riso e o choro teriam de ser praticados fora da sala, quando houvesse oportunidade. O jogo, o grande inimigo da disciplina, deveria ser banido das instituições escolares. Quando muito, domesticado, aturado na hora do recreio, se ele houvesse (2006, p. 127).

Esta escola, no entanto, não faz mais sentido na sociedade atual, como salienta José Sterza Justo:

A escola, no entanto, tal como está estruturada, enfrenta obstáculos sérios para lidar com as demandas desse sujeito contemporâneo, nômade, múltiplo, diverso, expandido, flanador e tribalista, que se constitui no movimento, na errância, no trânsito, no deslocamento de um lugar a outro em qualquer plano da vida: no geográfico, no social e no psicológico. Enquanto, pois, o sujeito contemporâneo se constitui num tempo e espaço ampliados, a escola continua com sua constituição fincada num tempo e num espaço constritos e fechados (2005, p. 39).

Visando, então, a formação de professores para o Ensino Fundamental, objetivo do curso de Pedagogia e do PIBID, propusemos a realização de um curso que se caracterizasse por atividades lúdicas, envolvendo arte, cultura e criatividade, que fossem facilmente replicáveis nas escolas básicas de atuação das bolsistas e, mais do que isso, que inspirassem atividades diferenciadas por parte das pibidianas no contexto escolar. 


\section{Metodologia}

O curso contemplou seus objetivos iniciais de: refletir sobre o encontro do cinema e do teatro com a educação, problematizando a sua utilização nas escolas; ampliar o contato das estagiárias do PIBID com experiências relacionadas ao cinema e as artes cênicas; e desenvolver atividades práticas para o trabalho com cinema e jogos teatrais na sala de aula.

Foram, ao todo, dez encontros que, em seu conjunto, abarcaram atividades prático-teóricas envolvendo jogos e improvisações teatrais, brinquedos ópticos, exibição de filmes de curta e longa metragem, produção de vídeos, contação de histórias, visita ao Museu da Comunicação da UFV, reflexões sobre a atuação profissional na sala de aula, relatos e trocas de experiências. Em todos os encontros, buscou-se estimular o protagonismo das estagiárias sobre as ações desenvolvidas por elas nas escolas com a apropriação sobre as atividades de cinema e teatro realizadas no curso.

O espaço escolhido para realização do curso foi o Laboratório Interdisciplinar de Formação de Educadores (LIFE): uma sala ampla com uma gama de recursos disponíveis como jogos didáticos, livros, computadores, equipamento multimídia, lousa digital, mesas circulares, sofá, mapas, tabelas, alfabetos em libras, entre tantos outros. Enfatizamos que muitos desses materiais não foram utilizados no desenvolvimento do curso, mas a mensagem cotidiana dos encontros, emitida por este espaço físico, remetia a uma outra estrutura de sala de aula e possibilidades de recursos à disposição do grupo.

As artes constituem modos específicos e diferenciados de produção de conhecimento, abarcando diversas linguagens e formas sensoriais, além de uma expressão característica de cada abordagem artística. Escultura, dança, música, pintura, circo, cinema, teatro, entre outras, performam distintas linguagens e meios de expressão, com variantes internas, inerentes a cada uma delas, possibilitando tratamento em separado, conforme suas singularidades. No entanto, a representação 
teatral, os jogos dramáticos e as improvisações com construção de personagens permitem o trânsito, uma incursão pelas diferentes linguagens. "O teatro é um pot-pourri de linguagens" (LEAL, 2000, p.100). O mesmo podemos falar sobre o cinema que também abarca diferentes linguagens em sua realização.

Cientes de que o curso não destinava-se a profissionais das artes, muito menos à formação de artistas, almejávamos que as experiências artísticas, estéticas, lúdicas e criativas vivenciadas pelas estudantes da Pedagogia se somassem às suas vivências pregressas e possibilitassem novos olhares e rearranjos sobre as próprias experiências como estagiárias e futuras docentes. Neste sentido, as atividades teatrais desenvolvidas visaram tanto mobilizar o potencial criativo por parte das participantes quanto promover reflexões sobre as relações pessoais, o corpo, a arte e o lúdico na escola e em sala de aula.

Os jogos dramáticos, além de serem acessíveis, constituem recursos pedagógicos extraordinários (MÁRQUEZ, 1996). Abarcam uma metáfora da realidade, pois implicam em regras e criatividade na resolução de problemas propostos e seu desenvolvimento mobiliza os sentidos e a criação estética (SPOLIN, 2007). Em sua maioria, os exercícios e jogos teatrais utilizados foram extraídos do arsenal do Teatro do Oprimido, cujos objetivos principais consistem no autorreconhecimento, na relação com os outros corpos e com o espaço, na interlocução expressiva da emissão e recepção de mensagens (BOAL, 1998) e na desmecanização do corpo e mente "alienados às tarefas repetitivas do dia-a-dia" (BOAL, 2005, p.16).

Foram utilizados exercícios e jogos das quatro primeiras categorias:

$1^{\mathrm{a}}$ - "Sentir tudo que se toca";

$2^{\mathrm{a}}$ - "Escutar tudo que se ouve";

$3^{\mathrm{a}}$ - "Ativando os vários sentidos" e;

$4^{\mathrm{a}}$ - "Ver tudo que se olha" (BOAL, 1998). 
As nomenclaturas de três dessas categorias remetem à necessidade de ir além da percepção física possibilitada pelos órgãos do sentido: Sentimos o que tocamos? Realmente escutamos os sons que nos chegam aos ouvidos? Vemos o que está perante nossos olhos? Flávio Sanctum explica:

Os jogos que se utilizam dos sons são classificados, em sua maioria, na segunda categoria de exercícios do arsenal do Teatro do Oprimido. Essa categoria tem o objetivo de sensibilizar os ouvidos a escutar tudo que somente ouvimos. Para Boal o ato de ouvir é algo físico, produzido pelo ouvido. Porém, precisamos perceber além dos sons e palavras que ouvimos, necessitamos também refletir sobre o que ouvimos e avançar para escutar. Assim, nessa categoria há exercícios de criação de movimentos e sons ritmados para desenvolver nos praticantes a sua percepção com o objetivo de burilar o sentido da audição (SANCTUM, 2012, p. 104).

A terceira categoria, "Ativando os vários sentidos", é composta, em sua maioria, por exercícios e jogos trabalhados com os olhos fechados. Como vivemos sob um monopólio da visão, nos privamos momentaneamente desse sentido para explorar os demais. Foram realizados exercícios individuais e em duplas, que exploraram principalmente o deslocamento, a audição e o tato. Além de aguçar a percepção de outros sentidos, as atividades com os olhos fechados implicaram também nas relações de confiança, de responsabilidade e cuidado com o outro, quando, em duplas, uma pessoa precisava conduzir a outra, de olhos fechados, pelo espaço.

Os jogos foram selecionados conforme os objetivos de cada encontro; outros foram adaptados para cumprirem melhor as necessidades da formação. Inicialmente realizamos exercícios visando a descontração e integração das pibidianas. Com o desenvolvimento do curso, buscamos aqueles que, por diferentes características, favoreciam a atividade pretendida, ou correspondessem às demandas surgidas no processo. Através dos relatos das pibidianas, percebemos o quanto era 
difícil utilizar outros espaços escolares e até mesmo as salas de aula que eram, em geral, muito pequenas. Assim, todos os jogos eram passíveis de reprodução em sala de aula; alguns deles, inclusive, com os estudantes sentados.

Alguns exercícios utilizaram a imagem, o som e/ou a palavra para fins de avaliação dos encontros. "A utilização da linguagem imagética nas práticas do Teatro do Oprimido tem o objetivo de facilitar a abstração e criação de metáforas da realidade, para uma reflexão dessa mesma realidade e sua transformação." (SANCTUM, 2012, p.105). Sua utilização para fins de avaliação permitia tanto a criação e expressão por meio de imagens, projeções com reflexões sobre as imagens criadas e reorientação das atividades.

Contações de histórias também foram realizadas a partir de narrativas livres, improvisações e materiais variados, como papéis, tecidos, sucatas, entre outros. Em sua maioria, buscaram a interação das participantes por meio de respostas, marcação de ritmos ou canto. E possibilitaram transpor uma imagem relatada pela grande maioria das participantes sobre as contações nas escolas, feitas quase que exclusivamente, a partir da leitura e mostrando as gravuras, com o livro de literatura infantil em mãos.

É importante a compreensão da arte no currículo escolar na busca de implementação de uma educação centrada na formação humana, entendendo o educador como mediador dos conhecimentos, de práticas e de criações individuais e coletivas. As linguagens artísticas presentes no currículo escolar representam uma fonte de vivência através da apreciação artística, do desenvolvimento do senso crítico e das experiências estéticas e consequentemente, como caminho socializador do educando (CANDA e BATISTA, 2009, p. 109).

No que tange ao cinema, compreende-se que muitas vezes o audiovisual é apropriado na escola como um instrumento pedagógico, seja para ilustrar o conteúdo de uma disciplina ou suscitar o debate de algum tema, como também para proporcionar um momento de 
entretenimento aos alunos ou até mesmo preencher um horário vago. Porém, ao considerar o ato de ver filmes como alternativa para sair da rotina e utilizá-lo apenas para os propósitos citados anteriormente, talvez pela desconhecida bibliografia sobre cinema e educação e a própria dificuldade de acesso às diversas manifestações do cinema, se desconsideram todas as potencialidades de experiência estética, política e social possíveis com esta prática.

Segundo Inês Teixeira e José S. Miguel Lopes:

Não se trata de "escolarizar" o cinema ou de "didatizá-lo". Não estamos e não queremos concebê-lo ou restringi-lo a um instrumento ou recurso didático-escolar, tomando-o como uma estratégia de inovação tecnológica na educação e no ensino. Isso seria reduzi-lo por demais. Ao contrário, por si só, porque permite a experiência estética, porque fecunda e expressa dimensões da sensibilidade, das múltiplas linguagens e inventividades humanas, o cinema é importante para a educação e para os educadores, por ele mesmo, independentemente de ser uma fonte de conhecimento e de servir como recurso didático-pedagógico como introdução a inovações na escola (LOPES; TEIXEIRA, 2003, p. 10).

Além de refletir a respeito do encontro entre cinema e educação, os autores enfatizam a importância de que esta experiência toque primeiro os educadores que buscam no cinema uma possibilidade pedagógica. Por isso, apresentam a necessidade do engajamento dos educadores neste processo de mudança, neste novo olhar para o cinema dentro da escola.

Entendemos a educação como uma complexa e delicada arte de tecer vidas e identidades humanas, fazendo fruir as capacidades lógicocognitivas, estético-expressivas e etico-morais existentes, potencialmente, em cada criança e em cada jovem. Sabemos, ainda, que os educadores também devem ser educados, desenvolvendo tais capacidades e sensibilidades, para bem realizarem seu oficio e responsabilidade histórica e social. E como fazer fruir a experiência estética e a sensibilidade dos educadores, para que as fecundem em nossas 
crianças e jovens, sem nos lembrarmos do cinema, aqui entendido como manifestação artística, e não somente como parte da indústria cultural? (LOPES; TEIXEIRA, 2003, p. 9)

A partir desta pergunta geradora, alguns outros questionamentos nos apontaram uma nova possibilidade e a importância de trazer o cinema como pauta em nossa experiência com as bolsistas: Como aproveitar a potencialidade da experiência estética das artes, do teatro e do cinema, quando os próprios educadores, em formação, não se "alimentam" deles? Como emancipar o olhar, sem problematizar os meios de comunicação de massa e a publicidade? Como poderíamos mudar a velha e recorrente prática de utilização das artes, do teatro e do cinema em sala de aula, se os próprios educadores não experimentam, em sua vida particular, outras formas de fruir manifestações artísticas e experiências estéticas, aquelas que à primeira vista podem causar certo estranhamento? Porque o diferente, tantas vezes, é considerado ruim? Porque o silêncio, tantas vezes, é desconfortável? Será que o hábito, a cultura e as experiências artísticas poderiam transformar este cenário?

Se torna essencial, assim, a abertura, a disponibilidade e a vontade primeira dos educadores em serem personagens principais desta mudança, nesta nova forma de olhar o encontro das artes com a educação, principalmente ao se conscientizar de que esta prática traz consigo um gesto emancipatório em diversos âmbitos - político, cultural, estético e social. Além da participação ativa dos educadores, se faz necessário também refletir sobre a própria escola, as normas e as redes que existem (e resistem) dentro dela: existe um currículo disciplinar prévio a ser cumprido pelos educadores durante o ano letivo, que inclui saberes específicos das disciplinas e atividades paralelas de entretenimento, cultura e lazer, mas que não necessariamente incluem a experiência através da obra de arte para os alunos - mesmo nas próprias disciplinas de arte-educação. Segundo Barbero (2001), a escola está fundamentada em um regime de saber que se limita aos livros e desconsidera um aprendizado para além dos rendimentos escolares 
comprovados por pacotes de conteúdos memorizados em cada idade. Por isso existe uma:

[...] antiga e pertinaz desconfiança da escola para com a imagem, para com sua incontrolável polissemia, que a converte no contrário do escrito, esse texto controlado, de dentro, pela sintaxe e, de fora, pela identificação da claridade com a univocidade. Não obstante, a escola buscará controlar a imagem a todo custo, seja subordinando-a a tarefa de mera ilustração do texto escrito, seja acompanhando-a de uma legenda que indique ao aluno o que diz a imagem (BARBERO, 2001, p. 57).

Poderíamos dizer que esta postura, um tanto quanto controladora das escolas com relação à imagem, fomenta um ciclo de aprendizados reproduzidos repetidamente com o intuito de "educar através da imagem", mas não necessariamente contribuir para a emancipação do espectador, a livre interpretação, fruição e experiência dos educandos. E assim como quem respira, nós vemos - e olhamos - e para o desenvolvimento da criança ou do adolescente é fundamental dialogar não apenas sobre o que se olha, mas também sobre como se olha. Boal afirma que tão grave quanto o analfabetismo das palavras é o analfabetismo estético. "A castração estética vulnerabiliza a cidadania obrigando-a a obedecer mensagens imperativas da mídia, da cátedra e do palanque, do púlpito e de todos os sargentos, sem pensá-las, refutá-las, sequer entendê-las!" (BOAL, 2009, p.15).

Em nossa cultura contemporânea e na indústria cultural de massa, em que a sociedade está imersa em um universo de imagens e sons excessivos, em que diariamente são bombardeadas informações visuais através das mídias, as crianças também são constantemente submetidas a esses estímulos. Sendo assim, o exercício do olhar, a partir do momento que inaugura um pensamento sobre as coisas e sobre o mundo ao redor, poderia impulsionar a formação da criança, auxiliando no seu processo de desenvolvimento cognitivo e social. 
Nosso mundo cotidiano está cada vez mais sendo dominado pela imagem. Há uma pesquisa na França mostrando que $82 \%$ da nossa aprendizagem informal se faz através da imagem e 55\% desta aprendizagem é feita inconscientemente. Temos que alfabetizar para a leitura da imagem. Através da leitura de obras de artes plásticas estaremos preparando o público para a decodificação da gramática visual, da imagem fixa e, através da leitura do cinema, da televisão e dos CD-ROM o prepararemos para aprender a gramática da imagem em movimento. Preparando-se para o entendimento das artes visuais se prepara para o entendimento da imagem quer seja arte ou não (BARBOSA, 2012, p. 35).

Ainda de acordo com a autora, a escola é a instituição, ou espaço, que poderia (e deveria) tornar possível o acesso às artes e, mais ainda, "exercer o princípio democrático de acesso à informação e formação estética de todas as classes sociais, propiciando-se na multiculturalidade brasileira uma aproximação de códigos culturais de diferentes grupos" (BARBOSA, 2012, p. 34).

Pensando o cinema como imagem em movimento e como arte, o encontro do mesmo com a educação dentro da sala de aula, portanto, poderia se tornar um catalisador para o desenvolvimento da criança. Não apenas por estimular seu olhar, mas pela experiência que proporciona por meio da fruição da obra de arte: o reconhecimento de si e do outro, como indivíduos singulares de pensamento, reflexão e sensibilidades diferentes; pela inauguração de um universo de subjetividades por meio da imagem e do som; pela ampliação do repertório visual da criança; pelo incentivo ao (re)conhecimento de algo próximo do seu universo e pela possibilidade de se surpreender ao descobrir algo novo; e pela própria alteridade e deslocamento que o cinema traz para dentro da escola. Algo que poderia apresentar talvez até um novo fôlego para a formação de professores, para a prática pedagógica e para a própria escola. Para Adriana Fresquet, 
quando a educação - tão velha quanto a humanidade mesma, ressecada e cheia de fendas - se encontra com as artes e se deixa alagar por elas, especialmente pela poética do cinema - jovem de pouco mais de cem anos - renova sua fertilidade, impregnando-se de imagens e sons. Atravessada desse modo, ela se torna um pouco mais misteriosa, restaura sensações, emoções, e algo da curiosidade de quem aprende e ensina. Com o cinema como parceiro, a educação se inspira, se sacode, provoca as praticas pedagógicas esquecidas da magia que significa aprender, quando o "faz de conta" e a imaginação ocupam lugar privilegiado na produção sensível e intelectual do conhecimento (FRESQUET, 2013, p. 19).

Considerando esses apontamentos, assim como nas referências para as atividades teatrais, foram propostas reflexões e experiências que visassem a emancipação das pibidianas nesta busca de alternativas em sua prática pedagógica e da desmecanização dos corpos e mentes. Dos dez encontros, quatro tiveram o olhar, a imagem e o cinema como elementos a serem experimentados de maneira mais imersiva: uma dinâmica ativa de reflexão e intervenção lúdica em fotografias, pinturas, grafites, esculturas e outras imagens icônicas da história da arte; um breve histórico do cinema mundial, complementado por uma experiência de confecção de brinquedos ópticos; uma prática do fazer cinematográfico, através do exercício "Minuto Lumière"; e a fruição de uma sessão de gêneros variados, e por muitas delas desconhecidos, de curtas-metragens.

Considerando o acesso às mídias móveis para a produção de conteúdo, como o uso do aparelho celular, e o aparato técnico que compõe a lista de equipamentos existentes nas próprias escolas, como datashow e a caixa de som, as experiências propostas também eram passíveis de reprodução em sala de aula, com a diferença de que estas demandam planejamento prévio, devido à necessidade da utilização de equipamentos para a realização das mesmas. 


\section{Considerações finais}

O curso "Cinema, Teatro e Criatividade: experiências possíveis para reinvenções na escola" foi oferecido no primeiro semestre de 2016 e os impactos deste foram avaliados a partir dos relatórios mensais nos quais as pibidianas apresentaram o que observaram e realizaram na atuação nas escolas.

Identificamos, nestes relatórios, que algumas pibidianas tentaram aplicar o que estavam aprendendo no curso (isso foi solicitado e incentivado, mas nunca exigido). Houve algumas dificuldades já que as pibidianas estão apenas oito horas semanais nas escolas e, algumas vezes, as professoras regentes fazem pedidos de apoio às atividades escolares (confeccionar cartazes, lembrancinhas, fazer recortes, acompanhar alunos com dificuldades dentro e fora de aula) e nem sempre davam espaço para atuação das bolsistas, embora ficasse definido que duas horas quinzenais fossem para regência das estagiárias, ou seja, com atividades preparadas e desenvolvidas pelas pibidianas com os estudantes.

A partir do curso, foi possível perceber que as bolsistas passaram a ter uma postura mais crítica a atividades artísticas que já vem prontas para serem finalizadas pelas crianças, muitas vezes, seguindo uma única orientação dada pela professora. Além disso, as pibidianas inseriram algumas atividades lúdicas em sala de aula, que foram muito bem recebidas pelos estudantes e deram a elas o desafio de lidar com maior agitação, barulho e os efeitos das mudanças no ambiente de sala de aula. Apesar de afirmarem a importância do lúdico na educação, pibidianas e professoras da escola básica nem sempre consideram que uma atividade envolvendo maior movimentação do corpo tem caráter de ensino. Há uma percepção de que brincadeira e aprendizagem não se misturam e que andar, correr, cantar, pular, sair da sala, rir e conversar são vistos como indícios de indisciplina e, como os espaços das escolas em que atuamos são muito pequenos e mal distribuídos, a agitação de 
uma turma ressoa nas demais e, às vezes, dificulta o trabalho de outras turmas.

Quanto ao cinema, foi possível observar a abertura para outras possibilidades, já que nenhuma escola apresentava curtas-metragens para seus alunos e que os filmes utilizados eram direcionados ao público infantil pela indústria de comunicação de massa. A partir do curso, outros materiais audiovisuais foram levados para a sala de aula e as pibidianas chegaram a produzir um pequeno vídeo, o que as colocou na posição não somente de espectadoras, mas também de protagonistas na elaboração de uma história audiovisual. O último encontro do curso aconteceu no Museu da Comunicação da UFV onde aprendemos como a comunicação se transformou ao longo dos anos e o quanto o processo de comunicar envolve seleção e criatividade.

Esta experiência interdisciplinar é incomum no curso de Pedagogia da UFV e veio a favorecer uma ampliação do universo cultural e pedagógico de todas as participantes. Em uma cidade do interior de Minas Gerais, o contato com outras produções cinematográficas e com atividades teatrais é limitado. Além disso, todos os níveis de ensino privilegiam um modelo de ensino conteudista, com pouca participação dos estudantes e quase completa imobilidade corporal. Não se esperava que o curso, por si só, revolucionasse as propostas das pibidianas para o ensino, até porque, como afirma Jorge Larossa Bondía, para que a experiência aconteça é preciso “... ter paciência e dar-se tempo e espaço" (2002, p.24). No entanto, observamos que foi possível criar novas percepções e sensações sobre o efeito da arte, da cultura e da criatividade no processo de ensinar e de aprender. Neste sentido, acreditamos que o curso cumpriu o seu objetivo de fomentar novas experiências educativas que fossem inspiradoras para a prática das pibidianas de Pedagogia em atuação nas escolas básicas do ensino fundamental, hoje e no futuro. 


\section{Referências}

BARBOSA, A. M. A imagem no ensino de arte. São Paulo: Editora Perspectiva, 2012. BERGALA, A. A hipótese-cinema. Rio de Janeiro: Booklink; CINEAD-LISEFE/UFRJ, 2008. Disponível em: <https://www.scribd.com/doc/188001927/ BERGALA-Alain-A-Hipotese-Cinema>. Acesso em 20 de junho de 2016.

BOAL, A. A Estética do Oprimido. Rio de Janeiro: Garamond, 2009.

BOAL, A. Teatro do Oprimido e outras poéticas políticas. $7^{\text {a }}$ ed. revista e ampliada. Rio de Janeiro: Civilização Brasileira, 2005.

BOAL, A. Jogos para atores e não atores. Rio de Janeiro: Civilização Brasileira, 1998.

BONDÍA, J. L. Notas sobre a experiência e o saber de experiência. Revista Brasileira de Educação, n. 19, jan/abr 2002, p. 20-28.

CANDA, C. N.; BATISTA, C. M. P. Qual o lugar da arte no currículo escolar? Revista Científica/FAP, Curitiba, v.4, n.2 p.107-119, jul./dez. 2009.

FREIRE, J. B. Uma pedagogia lúdica. In: ARANTES, Valéria Amorim (Org). Humor e alegria na educação. São Paulo: Summus, 2006.

FRESQUET, A. Cinema e educação: reflexões e experiências com professores e estudantes de educação básica, dentro e "fora" da escola. Belo Horizonte: Autêntica Editora, 2013.

JUSTO, J. S. Escola no epicentro da crise social. In: LA TAILLE, Y. de. Indisciplina/ disciplina: ética, moral e ação do professor. Porto Alegre: Mediação, 2005.

LEAL, A. Teatro na Escola: da clausura à libertação. GARCIA, Regina Leite (Org.). Múltiplas linguagens na Escola. Rio de Janeiro: DP\&A Editora, 2000.

MÁRQUEZ, R. L. A saltos: el juego como disciplina teatral. Porto Rico: Ediciones Cuicaloca, 1996. 
MARTÍN-BARBERO, J. Disseminação do saber e novos modos de ver/ler. In: MARTÍN-BARBERO, J.; GERMAN, R (Orgs.). Os exercícios do ver: Hegemonia Audiovisual e ficção televisiva. São Paulo: SENAC, 2001.

TEIXEIRA, I.; LOPES, J. M. A escola vai ao cinema. Belo Horizonte: Autêntica, 2003.

PEREIRA, O. A. Pedagogia de Projetos. Revista de pesquisa científica - Fatea. Janus, Lorena, ano 1, no 1, 2o semestre de 2004.

PIBID. Apresentação MEC. Disponível em: http://portal.mec.gov.br/pibid. Acesso em 12 set. 2016.

SANCTUM, F. A Estética de Boal: odisséia pelos sentidos. Rio de Janeiro: Multifoco, 2012.

SPOLIN, V. Jogos Teatrais na sala de aula: um manual para o professor. Tradução: Ingrid Dormien Koudela. São Paulo: Perspectiva, 2007.

TARDIF, M.; LESSARD, C.; LAHAYE, L. Esboço de uma problemática do saber docente. Revista Teoria \& Educação. Porto Alegre, n. 4, p. 215-234, 1991.

Recebido: 27/10/2016

Received: 10/27/2016

Aprovado: 25/05/2017

Approved: 05/25/2017 